Invest. Pens. Crit. (ISSN 1812-3864; eISSN 2644-4119)

DOI: https://doi.org/10.37387/ipc.v8i3.173

Vol. 8, No. 3, Septiembre - Diciembre 2020

pp. $89-107$

\title{
La Poesía Hebrea-Panameña
}

\section{Luis Wong Vega, Ph.D.}

${ }^{1}$ Dirección de Investigación y Desarrollo, Universidad Católica Santa María La Antigua (USMA), Panamá, República de Panamá.

*Autor para Correspondencia. E-mail: lwong@,usma.ac.pa

Recibido: 12 de abril de 2020

Aceptado: 27 de mayo de 2020

\section{Los hebreos en el mosaico panameño.}

Panamá es un estado multiétnico. Las expresiones de esta diversidad se manifiestan en todos los órdenes de la vida del país, en mayor o menor medida, pero siempre con expresiones que evidencian su presencia y que aportan riqueza a la amalgama resultante que es nuestra panameñidad.

Según el escritor Edilberto Gonzáles Trejos, “descendientes de los “anusim”, marranos o criptojudíos procedentes de la Península Ibérica, han vivido en Panamá desde comienzos del siglo XVI” (1). Añade este autor que "judíos, tanto sefaradim como ashkenazim, comenzaron a arribar a Panamá en cantidades importantes, recién a mediados del siglo XIX, atraídos por alicientes económicos tales como la construcción del ferrocarril bioceánico y la fiebre del oro en California” (íbidem).

En un trabajo periodístico publicado en el diario español El País, de hace, más o menos, un lustro, se hizo un estimado de la población judía en Panamá. El autor señalaba entonces que: "la comunidad judía panameña oscila entre 15.000 y 17.000 integrantes, de los que de 9.000 a 12.000 son descendientes de los sefardíes, según diversos cálculos de las organizaciones hebreas de Panamá” (2). Probablemente, esta población podría rondar las veinte mil personas hoy en dìa.

La comunidad judía ha hecho aportes sustanciales a la institucionalidad panameña, particularmente en el ámbito socio-cultural. La autora Leizel Verbel señala que "gracias a la colaboración de la comunidad judía de Panamá, se estableció el Cuerpo de Bomberos de Panamá, la Orquesta Sinfónica Nacional, la Universidad Tecnológica, por mencionar las más notorias. Más recientemente se inauguró el Biomuseo de Panamá, con una sustancial donación de la comunidad judía” (3). 


\section{La presencia judía en la cultura.}

Dado el relativamente pequeño tamaño de la comunidad judío-panameña, podría pensarse que el número de artistas e intelectuales de raigambre hebrea sería relativamente bajo.

Por otro lado, según muestran diversos estudios sobre la presencia judía en las artes y la literatura en Latinoamérica, en muchos casos, la participación de los hebreos es significativamente alta, yéndose mucho más allá de la proporción a esperar, según el tamaño demográfico de la población judía en determinado país.

En algunos textos ilustrativos sobre el tema, la presencia de escritores panameños es exigua. El autor Isaac Goldenberg, en su texto "El Gran Libro de América Judía” (4), menciona solamente a un autor panameño (Enrique Jaramillo Levi), en un listado de varios cientos de autores judío-latinoamericanos. En otro listado más reciente, centrado también en escritores judío-latinoamericanos, se menciona solamente a un prestigioso profesor e intelectual californiano (Murray Baumgarten) que nació en Panamá pero que emigró a Estados Unidos desde muy joven y no ha mantenido vínculo alguno con Panamá, ulteriormente (5).

Esto, muy probablemente se deba a la escasa visibilidad que tienen el arte y la literatura panameños, en general, fuera de las fronteras del Istmo, por causas que debieron ser atendidas hace mucho tiempo.

En los últimos años, la presencia de intelectuales y artistas judío-panameños ha ido aumentando gradualmente, tanto en visibilidad como en número. La participación de intelectuales de origen hebreo (v.gr. el historiador Alberto Osorio, el abogado Saul Maloul, la profesora Irina de Ardila), cineastas (Abner Benaím, Arian Abadi), teatristas (Aarón Zebede, Masha Armuelles), narradores (Claudio de Castro, Dani Kuzniecky), pintores (Nessim Bassán) entre otros, es muy relevante en el entorno cultural panameño.

Respecto a los poetas y luego de una búsqueda en algunas de las pocas bases de datos en bibliotecas y en línea (6) y de mucha investigación bibliográfica, hemos podido identificar la obra de diez poetas panameños de origen hebreo, de diferentes épocas.

Estos son: Michael DeLevante, Eduardo Maduro, José Guillermo Ros-Zanet, Benjamín Ramón, Enrique Jaramillo Levi, Dora Posternak, Rogelio Pretto, Samuel Bassán, Vivian Nathan y Deborah Wizel.

Este grupo no es homogéneo: hay mayoría de sefaradíes sobre azkenazíes, hay ortodoxos y mesiánicos, hay no practicantes y/o agnósticos, hay mayoría de hombres sobre mujeres, en fin, hasta en esta muestra tan pequeña hay diversidad.

\section{La poética de los judíos en Panamá.}

Los escritores judíos tienen un gran peso en la literatura mundial contemporánea, incluyendo la poesía. Desde Kafka, Saúl Bellow, Isaac Singer, Elías Canetti, Boris Pasternak, Brodsky, Nadine Gordimer, 
Elfriede Jellinek, Harold Pinter hasta Allen Ginsberg, Bob Dylan y Amos Oz, la presencia judía en las letras universales es incontestable.

Según el autor argentino José Metter, sobre los grandes temas de la literatura judío-latinoamericana, "a través de los cuales se puede interpretar el judaísmo latinoamericano", habría que listar, principalmente, "la migración, el exilio, la errancia, la asimilación, el lugar de la memoria y del olvido, la hibridez, el antisemitismo, el pluralismo cultural, la identidad nacional y la relación entre Israel y la diáspora" (7).

¿En qué medida esto se cumple esta recurrencia en los poetas judío-panameños, reflejándose en su obra? ¿Hay temas diferentes, derivados de su experiencia de vida en Panamá? Para tener una idea, es necesario estudiar ejemplos paradigmáticos de su trabajo poético.

Michael DeLevante (מלוונטה) fue un norteamericano que migró a Panamá, para trabajar con la compañía del ferrocarril, a fines del siglo XIX. En 1894, el poeta Delevante publicó en Aspinwall, Republic of Colombia, su primer libro de poemas "First Blossoms". En 1906 publicó "Panama Songs". Fue, muy probablemente, el primer poeta de origen hebreo (sefaradî) en Panamá.

\section{A COLON SUNSET.}

Like forest-fires, illuming, far and wide, Some sylvan scene and desert leagues away, Last evening shone, all radiant on the tide, The last expiring embers of the day!

Soft clouds of crimson, floating down the West,

With glory crowned the distant bluffs and high;

All flushed and dreamy sank the day to rest

In twilight's arm outstretched athwart the sky.

Yon "Toro Point," that skirts the watery way, With soft suffusion 'neath the Heavens glowed ;

What wondrous hues reflected o'er the Bay As Night came stealing up the starry road! Calm was the eve peace brooded on the deep;

The stars, all shining, warned the hour of sleep.

April, 1893. 


\section{RETRENCHMENT.}

The impending blow, that hath fallen at last, Hath my old-time stipend sundered!

I feel the "cut" of the ten-per-cent. blast

On my three score pesos and hundred!

I'll have to do some "home cutting" too,

To the tune of sixteen gold dollars:

Eat one meal a day till they raise my pay

Wash my own clothes, my cuffs and my collars,

July, 1894.

Eduardo Maduro Lindo fue un importante intelectual y figura pública judío-panameña, durante la primera mitad del siglo XX. Fue contador y autor de una obra poética amplia, que incluye letras de importantes marchas patrióticas panameñas. Falleció en 1966.

\section{MARCHA PANAMÁ...}

Panamá, la patria mía, suelo grato, encantador Hoy te canto, Panamá, con alegría; al mirarte así grandiosa, cuando veo tu bandera de precioso tricolor, abrazarte con gran júbilo quisiera expresándote mi amor.

Panamá del alma de tus selvas he escuchado los rumores; siempre gocé tu calma y en tu cielo ví magníficos colores.

Panamá querida, ¡Oh! permite que yo muera en tu regazo; tuya será mi vida.

Sigue siendo libre, bella Panamá. 


\section{VIDA}

Oye: la vida nos prodiga tanto, que nos da la salud y la tristeza.

Gocemos, que no existe el desencanto, cuando sólo miramos la belleza.

Entonemos, entonces, nuestro canto

a la vida, que es luz y fortaleza.

Mañana, no sabemos si con llanto

mojaremos la flor de la pureza.

Oye: la vida tiene sus dulzuras

y no es preciso ver las amarguras, ni pensar en lo adverso de la suerte.

Bailemos, pues, la alegre zarabanda, con furor, como el mundo lo demanda, sin saber que bailamos con la Muerte.

\section{A SHERRIE}

Una blanca margarita en un hermoso pensil, un canto suave de alondra, una sonrisa sin fin, una brisa muy ligera en una tarde de Abril y un sol que brilla sereno en el lejano confín. Todo eso tú me pareces, Sherrie, graciosa y feliz, al llegar a los quince años, llena de venturas mil.

Que Dios bendiga por siempre la gloria de tu vivir.

José Guillermo Ros-Zanet fue médico pediatra y escritor. Con una extensa obra literaria que incluyen el ensayo y la poesía. Por muchos años fue docente y se retiró de la Universidad de Panamá habiendo ostentado cargos y honores. Falleció en 2018. 


\section{SIGNO}

Todo era la noche:

negro barro

y hojas negras,

llanto amargo.

Sangre y signo de mi sueño taumaturgo, de mi vertical

acento de amor desesperado.

Voz astral de lirio y nardo.

\section{ORIGEN}

Huyen los pájaros profundos.

Mar y rocas y vértebras de peces

subyacen tras la imagen primitiva

de este sueño que yo sueño.

Noble junco y ciega flor de siempreviva

lo circundan.

(Ya retornan sus huesos a mis huesos).

Arcángeles de sal y clorofila

edifican su luz aborigen, liberada.

Viva forma reintegrada a mi voz, marina, vegetal y exacta.

\section{LA POESÍA}

Y dura

bien nacida, y sigue,

piedra dura,

durando hasta la vida, piedra pura.

Y muy duro le dan

entre las sombras;

pero sigue nombrando

hasta las médulas,

y sigue hablando duro, en piedra pura. 
Y le tiran cadáveres

y espantos

y sigue tercamente

subiendo a puntapiedras,

a piedra perdurable

y pedregosa.

Y para hacerla leña

llegan oscuros,

mudos.

$\mathrm{Y}$ sin embargo sigue

piedra siempre total

y duradera.

Tenaz piedra encendida,

piedra siempre cabal

y bien nacida.

¡Verdad tan verdadera

-la piedra-la Poesía!

Benjamín Ramón es colonense. Hizo estudios de Filosofía e Historia en la Universidad de Panamá. Activo miembro del desaparecido Frente de Trabajadores de la Cultura y colaborador del antiguo INAC en la creación de talleres literarios. Actualmente edita la revista Camino de Cruces.

\section{EPIFANIA}

Inútil la verdad.

Fue inútil

decir

que la mano no mentía líneas para ancha la vida.

Inútil el mar.

\section{LA CORBATA}

Papá era obrero de la construcción

Papá era mecánico de autobuses

Papá era constructor, albañil

Papá era chofer y camionero

Pará era carpintero y artesano

Recuerdo qué alto volaban

sus cometas

a principios de año

Era un soñador

Apenas se puso una corbata

se murió

qué vaina. 


\section{PALABRA(S) HUECA(S)}

Aquí en Panamá

en Atlapa

(atlapadas)

las palabras andan sueltas

chocando contra las ventanas

como bala perdida

o mariposa

extraviada.

Hombres y mujeres de medio mundo

(atlapados)

no distinguen verdad o mentira

verbo o adverbios

sustantivos o adjetivos.

Aquí

en este país angosto

ajeno

el día romperá las ventanas

las palabras huecas

chocan contra las paredes.

Amanecerá y veremos.

\section{ISTMICA TÚ}

Toda entera tú pareces istmo grave: seno tuyo, la bahía; cuerpo tuyo, el istmo de cabo a cabo, y sensual región tierna - angostura de tránsito tu enamorada ruta: sexo y espacio para el encuentro de límite preciso.

Enrique Jaramillo Levi Licenciado en Filosofía y Letras con énfasis en Inglés, Magister en Creación Literaria y Magister en Letras Hispanoamericanas. Realizó estudios de Doctorado en Letras Iberoamericanas en la Universidad Nacional Autónoma de México. Posee una extensa obra, cubriendo casi todos los géneros literarios.

\section{MIRADA INTERIOR}

Qué grato levantarme todas las mañanas

sabiendo que pude no lograr hacerlo.

Qué maravilla poder dar gracias

por la salud, el amor y el entusiasmo que perviven. 
Qué ganas, en fin, de vivir eternamente.

Pero ha llegado el momento de explorar hacia adentro, de tratar de entender lo que soy,

lo que ansío ser.

Con sosiego y fe me inicio en las minucias

de esta mirada interior,

ardua tarea

de buscarme,

descubrirme

a través de la escritura,

aunque en ello ocupe

el resto de la vida.

\section{ESA FUERZA}

Esa fuerza

vital

que decididamente

te nombra

cuando respiras

también a mí me nombra.

Esa energía

raizal

que inexorablemente

te nombra

al escribir

también a mí me nombra.

Ese impulso

tuyo y mío

-lector y poeta

que somos-

nos nombra.

\section{SEDUCCIÓN}

\section{I}

Debo admitir

que sí:

tengo un idilio

apasionado

-simultáneo y múltiple-

con la Palabra

y sus secuelas, esas otras fieles palabras 
que nunca faltan

cuando convoco

en la intimidad

a la primera.

II

Todas acuden al unísono,

presurosas,

solícitas,

a mi llamado,

y de golpe

se dejan seducir:

me dan sus mieles

en una sola entrega

generosa

-múltiple-

que recibo

boquiabierto,

fascinado,

agradecido.

Así nace este poema.

Dora Posternak nacida en Uruguay, llegó a Israel en plena juventud y fue admitida en el kibutz religioso Ein Zurim. Luego se graduó de enfermera pediátrica en Jerusalén. Contrajo nupcias con Jacobo Zebede Zakay, panameño, y su primer hijo Yosef nace en Israel. Ya su vida queda para siempre vinculada al país del istmo, donde posteriormente se radica y sirve en el Instituto Alberto Einstein, durante más de veintisiete años. Dos hijas, Marcela y Naomi, completan el hogar. Reside actualmente en Israel.

\section{EL AMOR NO ESTÁ EN EL TIEMPO}

El amor no está en el tiempo

Nadie te dijo

que el amor no está en el tiempo

y ahora

buscas en la ida

las horas que se fueron

corres tras el amor en infinito y vives al borde siempre al borde la dicha y de sus caminos.

El otoño ya llegó con sus días

agradables y un poco tristes

ya se acercan los fríos y las nieves

y aún crees que mañana

comenzará un mañana 
Que aquel amor ya se acerca, ya se acerca

y te encierras en tu encierro

y te condenas en el espejo de tu almohada

\section{EN MI AUSENCIA, A TZIPORA}

El rumor de sus alas aún me llama mi madre era un pájaro herido un instante olvidó que era pájaro que debía alejarse volando.

Se creyó mariposa y se fue esa noche de viernes en el espiral de la llama cuando encendieron las sabáticas velas una noche de principios de marzo cuando en Jerusalén todavía florece el almendro que cubre los llantos.

Ella se fue

y yo no estaba

El rumor de sus alas

aún me llama.

Lo que parecía imposible en nuestros días

es real y concreto; la patria está ahí esperando a

sus hijos dispersos. Israel es para los judíos. Si

invertimos la fórmula, la conclusión será siempre

la misma: los judíos son para Israel. Bien lo

ensañaron los sabios: subir a Israel equivale al

cumplimiento de todas las mitzvot.

Rogelio Pretto es un reconocido pintor nacional, siendo uno de los más activos exponentes de la plástica colonense durante varias décadas. Actor de teatro, radio, cine y televisión, ha ejercido una buena parte de sus talentos actorales en los Estados Unidos de América, además de Panamá. Reside intermitentemente entre Miami y Boquete.

\section{CAUSAS (PARA AMY WINEHOUSE)}






\author{
Hay razones \\ para desear \\ y otras para negar, \\ para justificar \\ y aceptar, \\ para querer \\ y olvidar. \\ Hay momentos \\ para ver, \\ y otros para \\ ocultar \\ lo que por dentro \\ observamos, \\ y afuera confrontamos \\ y no sabemos soportar.
}

\title{
SUEÑOS DE AZUL
}

El río de mis sueños azules, vasto, claro y sereno,

lleno de obstinadas pasiones, lleva en deliberada esencia, la nata de mi compleja existencia.

Rociado por cenizas tristes, traza su delirio clandestino precipitado hacia el destino, lavando residuos de penas que animan mis pesares.

Allá en su colorida orilla susurra el rugir del río el cantar de mudos actores que reviven mis dulces locuras en espejismos perfilados.

En busca de reflejos sinceros, en pastos de ideas despiertas, busca el inquieto cuerpo sus miles incautos sentidos venidos del manto estrellado. 
En acalorados recuerdos

hoy mis deseos se encuentran, nadando entre celestes bondades, en medio de anhelos chistosos

que gozan de paisajes desnudos.

En su ancho y amplio sin fin

traza sus sueños el río soñador, que me lleva fijo y derecho, al tierno descanso azul de nuevos días de miel.

Samuel Bassán, según el Directorio de escritores Vivos de Panamá, "participa en varias páginas y comunidades literarias en Internet. Sus trabajos han sido recogidos en la prestigiosa página Textonautas. La comunidad Encuentro Internacional de Poesía lo distingue entre poetas selectos, en donde participa como poeta invitado. Seleccionado por el proyecto: "Libro sin Tapas" para sus Muestras itinerantes de poesía, en el cual representa a su país, y en la edición de sus libros artesanales. Sus poemas han recorrido muchos países de América.

\section{ESCRITO XVII}

Entre capítulos

que niegan expiro.

Soy mancha

en tu piel;

cubrí tu silencio,

en ciertas noches

te mostré mi alma.

Por momentos, fui absuelto.

\section{ESCRITO XL}

Te colgué del cielo

Con hilos

de mariposas

Caminé sobre ellos

Me hice liviano.

\section{ESCRITO XLI}

Fuiste mar,

Algún infierno, Amanecidas mojadas, Sueños conclusos. 
Dormí

al otro lado

De un arroyo

Tomé manzanas

abordé trenes

caminaron sin rieles

yo miraba por la ventana.

\section{ESCRITO LX}

Hierro caliente, tormento apasionado.

No caves mi tumba

al tenerme por mis entrañas.

Poeta y verdugo

de mano propia

Sangras a placer.

Entre tinta

y papel,

haces de tu infierno

Una confesión

sopla con la vida.

Madrugadas.

Ella es la reina de marfil.

Viviane Nathan, también con biografía descrita en el Directorio de Escritores Vivos de Panamá y que dice que esta poeta "nace en Montevideo, Uruguay en 1953. A la edad de 9 años se traslada con sus padres a Lugano, Suiza, donde cursa parte de sus estudios primarios y secundarios. Termina estos en Panamá, a donde llega en 1967; y aquí escribe sus primeros poemas. Además del español, domina el italiano, francés e inglés. Graduada de Publicidad en la Universidad de Panamá. Reside actualmente en Jerusalén, Israel.

\section{VOY A APAGAR LA LUZ}

Voy a apagar la luz para quedarme a oscuras con tu rostro, para inventar de nuevo aquel instante: intimidad etérea y fulminante, piel en la voz, voz en el canto, en la mirada... 
Voy a apagar la luz

porque la oscuridad me obliga a dibujarte, me da la dulce libertad de juntar las ternuras, de calcar las ansias y borrar las soledades...

Voy a apagar la luz

para pensar en tí.

\section{HIMNO AL DESACATO}

Pienso violar todas las leyes, los órdenes, los ritos, los sistemas.

Voy a treparme a un árbol y a patear cientos de piedras, y caminando boca abajo quizá le vea el trasero a este mundo embalsamado donde todo lo que brilla apesta...

Quiero robarme un manojo de estrellas, pintar la luna de verde $y$ al sol ponerle una careta.

Así, cuando me tomen de la mano

y me lleven a una celda, cantaré un himno al desacato, me pondré las rejas en los ojos y entonces quedarán encerrados los de afuera...

\section{FINAL DE UN POEMA}

Dejaré las notas en su sitio, miraré más allá de los objetos, cantaré hacia adentro, como siempre, lloraré hacia fuera, tomaré el peso acostumbrado de mi cuerpo, giraré los pasos:

el futuro es un enigma... Sentiré no sé qué cosas y en las cálidas noches de estas tierras dormiré como muchos, con los ojos abiertos, con el alma despierta y mis pies sólo cubriendo la cama, en silencio. Yo no sé conjugar los infinitos verbos del idioma eterno... 
No te conozco, compañero.

Mi vida es agradable comparándola con otras, pero es escasa frente a mis expectativas.

Por eso te cuento

que cruzaré la vereda

y callaré

como siempre,

para que nadie se ría, para que nadie cuestione,

para que nadie sepa lo sola que me siento.

\section{SE ME ANTOJA}

Se me antoja que la vida es hermosa, sintiéndola entera, profunda

- ilimitada bajo la piel -

se me antoja inventar una manera nueva de decirte mil cosas y

siempre termino

sonriéndote en silencio, sonriéndome,

$\sin$ fin

una sonrisa -yo- toda vertical.

Deborah Wizel, según la página web Afinidades Electivas, “escribe cuentos y poesía a partir de los 8 años. Segunda mención de honor en el Concurso Maga de cuento breve 1996 con el cuento La Armadura. Tercer lugar en el Concurso Municipal León A. Soto, 2013 con Instantáneas de Dolor. Algunos de sus cuentos y poemas han sido publicados en antologías. En estos momentos escribe sus memorias (los primeros 50 años) y una novela".

\section{DIME}

"Afuera no hay canto de pájaros

y adentro un silencio sofocante se cierne sobre todos"

Ana Frank, Bergen Belsen (1945)

I

Annelies Marie

tu juventud se esparció en la tinta de tus diarios

La liberación llegó tarde

la fiebre tifoidea te venció faltando un mes

Dime... 
si no hubieses muerto

¿sabría quién eres?

II

Tantos diarios que no fueron escritos

Tantos adolescentes

-como tú-

que de la noche a la mañana enfrentaron su fatalidad

Dime Ana...

si hubiesen vivido

¿los conocería?

III

¿Cuántos desaparecieron?

¿Cuántos diarios se dejaron de escribir?

Y yo...

que rompí mis diarios

quemé las hojas

boté todo

borré mi historia

Dime Ana...

¿Cuándo yo muera

alguien me recordará?

\section{ÚLTIMO}

Por veinte noviembres

la esquina del ropero

telarañas reprimidas

La esperanza se arrugó colgada de la percha

La foto en el bolsillo perdió color

Eterna distancia

insondable espera

El último noviembre

Desparecí fronteras 
vestí deseo

peiné ansias

calcé lujuria

y salí a tu encuentro

\section{Epílogo.}

En 1916, en su libro Los Segundos Preludios, el principal poeta panameño Ricardo Miró, escribió el poema Alma Judía (8). La fascinación y el interés por lo judío siempre ha estado presente en muchos panameños, especialmente en la conciencia de aquellos que poseemos, muy lejanamente o más cercanamente, sangre marrana.

Los poetas panameños de ascendencia hebrea son cuantitativamente pocos. Curiosamente, haciendo la comparación con poetas de otras minorías étnicas en nuestro país, la minoría hebrea es, proporcionalmente hablando, la que tiene mayor número de poetas respecto al total de su grupo poblacional. Los judíos-panameños (20,000 personas, 10 poetas, $0.5 \%)$ superan a los afroantillanopanameños $(600,000$ personas, 56 poetas, $0.28 \%$ ) a los chino-panameños $(300,000,30$ poetas, $0.1 \%)$ y a los panameños de los pueblos originarios (400,000, 23 poetas, $0.05 \%$ ).

La poesía, como expresión del alma judía, data de los orígenes mismos de este pueblo y vive unida consustancialmente a su carácter, a su destino y a su virtud. La poesía judío-panameña, debe crecer en cantidad y calidad, integrarse en su riqueza no solo a la poesía panameña y latinoamericana sino también a la literatura hebrea mundial. Debe enriquecerse y florecer, en todas sus expresiones. Panamá, tierra de oportunidades, es campo fértil para ello.

\section{Bibliografía.}

1. González Trejos, Edilberto (2013). La comunidad judia en Panamá. Un acercamiento histórico. Conferencia dictada el 13 de febrero de 2013 en el Isrotel, Tel Aviv, en el marco de la 26 . Feria Internacional del Libro de Jerusalén, Israel.

2. Meléndez, José (2014). Los sefardies panameños, a la expectativa por obtener la ciudadanía española. Edición del 7 de abril de 2014. Diario El País, Madrid. España.

3. Verbel, Leizel (2014). La Etnia Hebrea en Panamá. Trabajo de curso. Licenciatura en Geografía e Historia. Facultad de Humanidades. Universidad de Panamá.

4. Goldenberg, Isaac (1998). El Gran Libro de América Judía. La Editorial, Universidad de Puerto Rico, Río Piedras, P.R.

5. https://jewishlatinamerica.wordpress.com/2018/03/02/murray-baumgarten-shape-shiftersmemories-a-panama-jewish-childhood/ 
6. http://www.cultura.utp.ac.pa/escritores/

7. José Metter (2000). Literatura judía en América Latina. Revista Iberoamericana. Vol. LXVI, Núm. 191, Abril-Junio 2000, 257-260.

8. Miró Denis, Ricardo (1976). Antología Poética. Impresora Panamá. Panamá. 